MULTIMODAL ANALYSIS OF PERSUASIVE STRATEGIES IN CANCER RISK MESSAGES IN POSTERS

\author{
Collin Jerome \\ Faculty of Language Studies and Communication Studies \\ Universiti Malaysia Sarawak (Malaysia) \\ jcollin@unimas.my \\ Su-Hie Ting \\ Faculty of Language Studies and Communication Studies \\ Universiti Malaysia Sarawak (Malaysia) \\ shting@unimas.my
}




\title{
MULTIMODAL ANALYSIS OF PERSUASIVE STRATEGIES IN CANCER RISK MESSAGES IN POSTERS
}

\begin{abstract}
Cancer remains as one of the most fatal diseases affecting human life today. Despite medical advances in cancer treatment, cancer mortality rates remain high and there is still much more to be done to raise public awareness about its risks and prevention. Posters are among the means to communicate cancer risk messages to target audiences to influence them to adopt recommended behaviours to minimise their risk of developing the disease. This paper presents an analysis of cancer risk messages in cancer prevention posters. Using multimodality and persuasive communication theory, the paper examines the posters' verbal and visual elements and how they converge in creating persuasive messages that aim to influence behaviour change among the target audience. To achieve this, five posters on cancer risk produced by the Ministry of Health Malaysia are chosen and analysed in terms of (1) their visual and verbal elements and (2) how they work together to produce persuasive messages with motivational appeals that can effectuate a change from harmful health behaviours to those that prevent cancer. The findings show that the posters' visual and verbal elements work metafunctionally (e.g. ideationally, interpersonally and textually) in creating cancer risk messages. The findings also show that the posters' visual and verbal elements converge with motivational appeals of fear, guilt and pity to produce persuasive messages that can induce people to change their behaviours and take preventive measures to reduce the risk of cancer. More importantly, the posters also promote the idea of cancerfree, healthy lifestyles.
\end{abstract}

Keywords: multimodality; metafunction; motivational appeals; cancer; health risk communication 